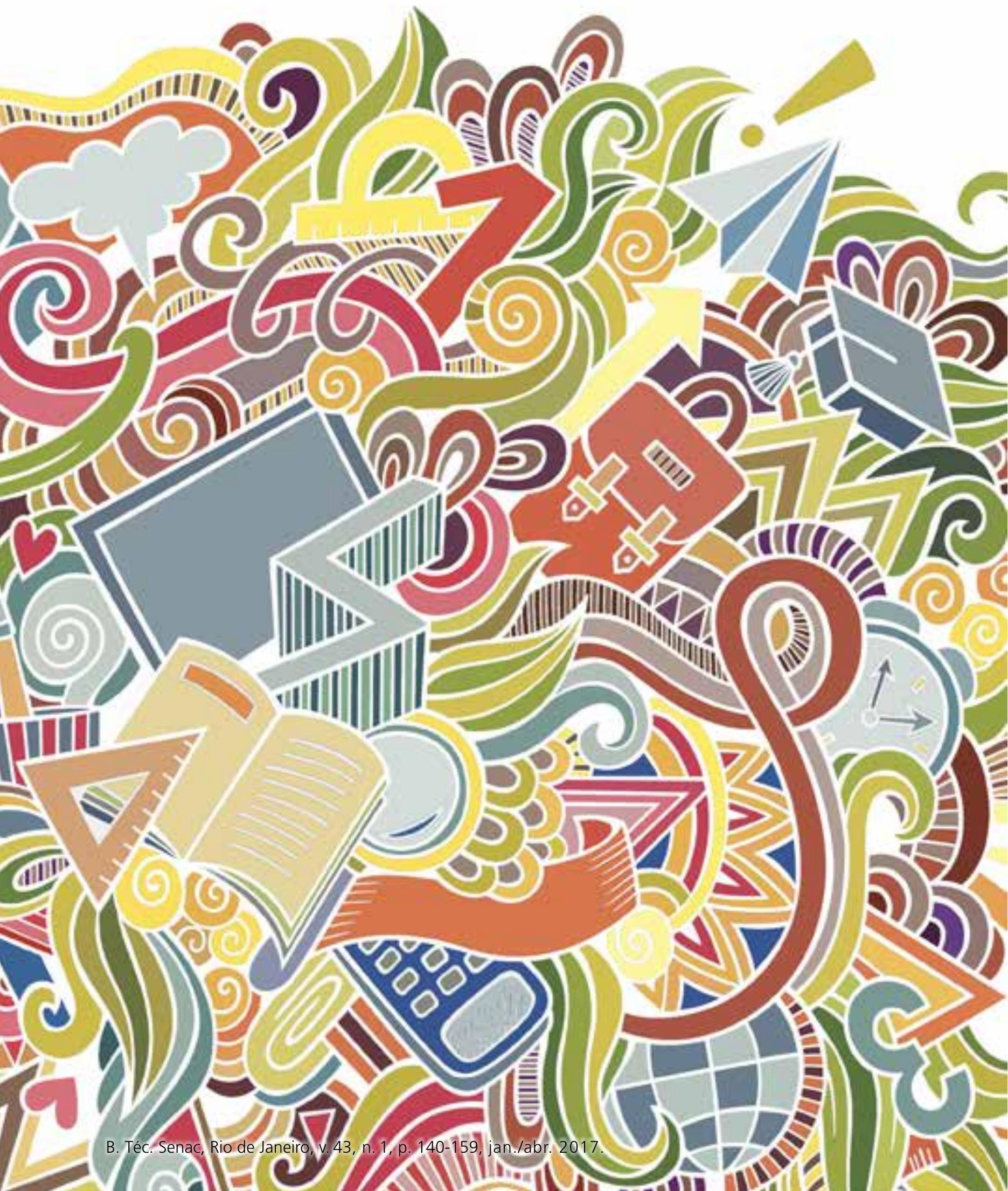


* Doutor em Educação pela Universidade Federal Fluminense (UFF), com especialização em Gestão do Conhecimento pela Universidade Federal do Espírito Santo (Ufes). Professor Adjunto II do Departamento de Educação, Política e Sociedade (Deps) do Centro de Educação da Ufes na linha de pesquisa Política, História e Cultura. Membro do Núcleo de Estudos sobre o Trabalho (NET) da Ufes. Coordenador do Laboratório de Gestão da Educação Básica do Espírito Santo (Lagebes), da Ufes. Membro do GT 09 (Grupo Trabalho e Educação) da Associação Nacional de Pós-graduação e Pesquisa em Educação (Anped). Membro do Observatório da Educação (Obeduc). Vila Velha, Espírito Santo, Brasil. E-mail: marcelo.lima@ufes.br

** Graduando em Pedagogia pela Ufes. Cariacica, Espírito Santo, Brasil. E-mail: renansperandio@gmail.com

Recebido para publicação em: 10.8.2016

Aprovado em: 31.1.2017

\section{INTEGRAÇÃO DO ENSINO MÉDIO À EDUCAÇÃO PROFISSIONAL NA REDE FEDERAL: OBSTÁCULOS E VIABILIDADES DA INTEGRAÇÃO CURRICULAR NO IFES}

\author{
INTEGRATING HIGH SCHOOL WITH VOCATIONAL \\ EDUCATION IN THE FEDERAL NETWORK: OBSTACLES \\ AND VIABILITIES IN CURRICULUM INTEGRATION IN IFES \\ INTEGRACIÓN DE LA EDUCACIÓN SECUNDARIA A LA \\ FORMACIÓN PROFESIONAL EN EL SISTEMA FEDERAL: \\ OBSTÁCULOS Y VIABILIDAD PARA LA INTEGRACIÓN \\ CURRICULAR EN EL IFES \\ Marcelo Lima* \\ Renan Sperandio**
}

\section{Resumo}

Este trabalho visa problematizar o processo de integração curricular de cursos técnicos. Especificamente, avalia, por meio de duas pesquisas, a adesão, operacionalização e viabilização da integração curricular do ensino médio com a educação profissional técnica de nível médio em cursos do Instituto Federal do Espírito Santo (Ifes) nos campi de Vitória e Venda Nova do Imigrante. Orientado teórico-metodologicamente pela perspectiva marxiana, conclui-se que esse tipo de curso se constitui em uma proposta contra-hegemônica tanto no nível macro - políticas nacionais de Educação Profissional Técnica e Tecnológica (EPT) - como no nível micro (no Ifes e nos campi).

Palavras-chave: Trabalho. Educação profissional. Integração Curricular. Ensino médio.

\section{Abstract}

This work aims to discuss the process of integrating the curricula of technical courses. Specifically, it uses two surveys to evaluate adhesion, operation and feasibility of high school curriculum integration with high school level vocational technical education courses at the Federal Institute of Espírito Santo (Ifes - Instituto 
Federal do Espírito Santo) in its Vitória and Venda Nova do Imigrante campuses. Theoretical and methodologically guided by a Marxian perspective, it is concluded that this type of course constitutes a counterhegemonic proposal both at the macro level - national vocational education policies for Technical and Technological Vocational Education (EPT) - and in the micro level (the IFES and campuses).

Keywords: Plan. Vocational education. Curriculum Integration. High school.

\section{Resumen}

Este trabajo se propone problematizar el proceso de integración curricular de los cursos técnicos. Evalúa específicamente, por medio de dos investigaciones, la adhesión, operacionalización y cómo se hace viable la integración curricular de la enseñanza secundaria con la formación profesional técnica de nivel secundario en los cursos del Instituto Federal do Espírito Santo (IFES), concretamente en los campi de las ciudades de Vitória y Venda Nova do Imigrante. Orientado desde el punto de vista teórico y metodológico por la perspectiva marxista, se ha llegado a la conclusión de que este tipo de curso se constituye como una propuesta antihegemónica tanto en el nivel macro - políticas nacionales de Educación Profesional Técnica y Tecnológica (EPT) - como en el nivel micro (en el IFES y en los campi).

Palabras clave: Trabajo. Formación profesional. Integración curricular. Educación secundaria.

\section{Introdução}

A educação secundária, no Brasil, apesar de sua expansão recente, não se universalizou e está muito distante de ser um direito social plenamente atendido. Melhorar a gestão e ampliar os recursos para educação é condição sine qua non para que o ensino médio (EM) e profissional deixem de ser tratados como mercadoria, tornando-se um direito, com acesso gratuito, universal e de qualidade.

A forma pedagógica mais adequada para a educação básica cumprir, em sua última etapa, o principal objetivo pedagógico da educação brasileira, é cumprir o que está previsto no artigo 205 da Constituição federal, o qual preconiza que a educação visa ao pleno desenvolvimento da pessoa, ao preparo para o exercício da cidadania e à qualificação para o trabalho, objetivos que devem ser articuladamente realizados. Para tanto, cumprir essa finalidade sem reproduzir o dualismo estrutural histórico que fornece um ensino médio terminativo para muitos e um ensino médio de preparação para o acesso 
ao ensino superior para poucos não é o que tem ocorrido. Para atender essa premissa, muitos autores criticam a forma adestradora e excludente da educação e preconizam a oferta de um ensino médio integrado à educação profissional técnica de nível médio pública de qualidade.

Segundo Ramos (2014), a educação integrada ocorre em "um tipo de escola que não seja dual, ao contrário, que seja unitária"; que garanta a todos "acesso à cultura, a ciência, ao trabalho por meio de uma educação básica e profissional". Uma educação que "possibilita a compreensão dos princípios científico-tecnológicos e históricos da produção moderna, de modo a orientar os estudantes à realização de múltiplas escolhas".

Assim, percebe-se a enorme complexidade pedagógica e epistemológica advindas da implementação da integração curricular dentro e fora de políticas como o Programa Nacional de Integração da Educação Profissional com a Educação Básica na Modalidade de Educação de Jovens e Adultos (Proeja).

Vários autores do campo Trabalho-Educação têm se debruçado sobre esta temática. Para citar apenas alguns, destacam-se aqui Frigotto, Ciavatta e Ramos (2005), Ciavatta, Ramos (2011), Moraes e Alavarse (2011), Silva (2011) e Menezes (2012), que ajudam a pensar esse tema extremamente complexo. Em geral, esses autores reconhecem que a materialização histórica da integração curricular não se esgota nos seus determinantes pedagógicos e escolares previstos na legislação, mas se articulam em questões mais amplas da própria sociedade. Ciavatta e Ramos (2011, p. 27) afirmam que "a dualidade e fragmentação no ensino médio e na educação profissional devem ser compreendidas não apenas na sua expressão atual, mas também nas suas raízes sociais". Para as autoras, "uma visão da totalidade social evidencia o sentido da disputa" que envolve "os recursos públicos" destinados à "educação profissional", a qual, muitas vezes, vê-se "reduzida ao mercado" (CIAVATTA; RAMOS, p. 27). Ou seja, "a travessia acidentada para a educação unitária, omnilateral, politécnica" que leve a "uma formação integrada do ensino médio e à educação profissional" (CIAVATTA; RAMOS, p. 27) indica que muitas são as questões estruturais que envolvem a integração curricular e que algumas obstam à generalização da integração como política pública.

Na visão de Menezes (2012, p. 1),

a integração encontra dificuldades em sua efetivação na prática pedagógica, devido à falta de diálogo entre as disciplinas, à formação departamentalizada dos docentes que, ao se perceberem envolvidos em um currículo que se pretende integral, apresentam sérias limitações na compreensão da inter-relação entre as áreas do conhecimento. 
Considera-se que a vinculação do ensino médio com o profissional fortalece pedagogicamente a reciprocidade dos saberes do currículo, dando mais capacidade formativa ao ensino geral e mais fundamentação científica e humanista, propiciando ao ensino técnico adensamento das relações entre os conteúdos teóricos e práticos, propedêuticos e técnicos.

A formação do educando não deve ser limitada apenas à aquisição de informações, mas, principalmente, à apropriação e transformação das informações recebidas, ou seja, da própria autonomia do conhecimento. Pensar um currículo integrado é pensar uma reorganização curricular em que o "espaço dos chamados conteúdos escolares seja redimensionado e redirecionado sem desqualificá-los, promovendo integração entre os saberes de formação geral e os de formação profissional" (BRASIL, 2006, p. 32).

Neste caso, "as áreas de conhecimento devem ser vistas como meios capazes de permitir ao aluno uma melhor compreensão de si, do outro, do mundo natural, social", econômico, produtivo "e do momento histórico em que está inserido" (BRASIL, 2006, p. 30).

Deve-se advogar uma formação que propicie interação orgânica dos saberes e que se relacione com uma totalidade histórica, engendrando-se como parte movida e movente da práxis humana. Essa integração depende de uma construção coletiva do conhecimento. Parte-se da premissa de que todo conhecimento é mediado por múltiplas formas de interação social e de práticas escolares viabilizadas pelo educador e partilhadas entre docentes e discentes (BRASIL, 2006, p. 30).

Apesar da importância da oferta de ensino propedêutico e profissional, esse não se tornou compulsório nem hegemônico no Brasil. Bremer e Kuenzer (2012, p. 1) problematizam a implementação do ensino médio integrado, ressaltando que existem inúmeros "desafios existentes para que a proposta conceitual seja de fato materializada na prática escolar, aspecto que encontra centralidade na pesquisa ora em desenvolvimento".

Para Moura, Lima Filho e Silva (2015), existem questões políticas, econômicas e ideológicas que atravessam as práticas educativas e curriculares de um país capitalista e periférico como o Brasil, as quais podem restringir a capacidade concreta em prover e implementar um ensino integrado e integrador. Não basta prever na lei, existe uma luta de classes que se articula com a divisão do trabalho, que separou e fragmentou historicamente a organização da sociedade e que permanentemente tende a separar em departamentos e isolar as práticas pedagógicas.

Silva (2011, p. 307) também aponta que ainda existem limitações presentes no processo de ensino "derivados, em parte, de interpretações divergentes 
do que seja integração curricular e da multiplicidade de significados atribuídos à ideia de trabalho como princípio educativo".

Moraes e Alavarse (2011, p. 810-811) indicam que, apesar de ser uma política curricular avançada, a integração do ensino médio à educação profissional ainda é uma contratendência à fragmentação curricular nada hegemônica. Segundo esses autores, em 2010, as matrículas no EM integrado atingiram apenas 215.533 alunos (2,6\% do total da oferta de ensino médio e profissional), portanto, há uma oferta residual da forma integrada e hegemônica da oferta subsequente.

Com efeito, as redes privadas e inclusive os Serviços Sociais Autônomos (o chamado "Sistema $\mathrm{S}$ "), na maioria dos casos, vêm optando, principalmente, pela oferta do ensino médio e técnico separadamente, com alguns casos de oferta articulada e, mais residualmente, integrada.

Nesse sentido, são as redes públicas, em função da legislação e de políticas indutoras, que vêm assumindo maior parte da oferta integrada. As redes estaduais de ensino médio de educação profissional (com destaque para o Paraná e Rio Grande do Sul) tomam essa oferta como parte integrante, mas não exclusiva.

A Rede Federal de Educação Profissional, por sua vez, por ser uma rede pública de ensino, mediante a qualidade de corpo docente e de infraestrutura física e pedagógica, seria mais adequada para a materialização desse modo integrado. Mas nem mesmo na rede dos Institutos Federais os cursos técnicos integrados tornaram-se regra geral. Eles apenas representam uma fração da oferta total, que se compõe ainda de cursos técnicos concomitantes e subsequentes e convivem também na mesma rede com a oferta de cursos de Formação Inicial e Continuada (FIC), de tecnologia, de graduação e de pós-graduação.

O que se pode perceber é que, se por um lado, no movimento histórico a partir de 1997, houve uma hegemonia da fragmentação curricular, com a separação do ensino médio e técnico, por outro, o fim do Decreto n. 2208/97 não implantou, de modo sistemático, as novas premissas da integração curricular. Ou seja, mesmo com o novo aparato normativo, que trouxe sustentação ao formato dos cursos técnicos integrados, à criação dos Institutos Federais e à política do Proeja, há uma série de resistências locais e nacionais que se opõem à hegemonização da integração curricular. Essa questão, cuja superação depende de um maior aprofundamento de questões políticas gerais, também tem a ver com questões de natureza pedagógica e epistemológica em circulação nos espaços de materialização dos cursos integrados. 
Moura (2014) alerta que o funcionamento curricular da escola não é fruto apenas de questões educacionais, mas resulta também da combinação de projetos societários em disputa, cuja resultante tende a superar ou reproduzir os traços históricos da dualidade educacional brasileira, que destina um tipo de ensino e de currículo para grupos sociais distintos.

Biancho Filho, Silveira e Oliveira (2016) apontam a importância dos atores envolvidos e indicam que a integração, para se viabilizar para além da legislação, depende dos sujeitos envolvidos, mas também deve ter em vista a busca por uma formação que leve o trabalhador a uma atuação autônoma. Considera-se que tal possibilidade precisa combinar o que diz a Constituição, articulando formação para o mundo do trabalho, mas também o preparo para o exercício da cidadania.

Para debater as dificuldades e possibilidades da integração curricular do ensino médio e do ensino técnico na Rede Federal, este artigo traz duas pesquisas que debatem as disputas internas travadas nas instituições, explicitando a decorrente complexidade da integração no interior dos Institutos Federais.

\section{A pesquisa: avaliando a organização da integração curricular na Rede Federal}

Na pesquisa 01, empreendemos uma sistematização das respostas dadas em formulário aplicado por ocasião da realização de seminário sobre integração, realizado em 2013. Nele, verificou-se a avaliação dos docentes sobre a integração curricular do ensino médio e técnico e sua viabilidade no Ifes.

Já na pesquisa 02, analisou-se o funcionamento da integração curricular informada pelos relatos dos docentes presentes às reuniões da pesquisa. Nessa pesquisa, procedeu-se à formação de um grupo de professores da educação geral e do ensino técnico que atuam no curso de Edificações do Ifes no campus em Vitória. Metodologicamente, esse grupo de participação voluntária tornou-se uma espécie de grupo focal.

\subsection{Função social da instituiição}

A instituição pública federal tem função social bastante ampla, mas situa-se na contradição entre transformar e reproduzir a sociedade, fazendo a mediação entre aquilo que as diferentes classes sociais esperam dela. De todo modo, nas pesquisas $01^{1}$ e $02^{2}$ buscou-se relacionar essa questão com a percepção de seus principais atores - os docentes. Esses profissionais da educação, na pesquisa 01, ao responderem sobre qual a "Função social da instituição de educação profissional" utilizaram com maior frequência nas
A instituição pública federal tem função social bastante ampla, mas situa-se na contradição entre transformar e reproduzir a sociedade

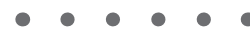


respostas as palavras: "Formação", "Trabalho", "Profissionais", com peso 6; "Mercado", "Conhecimento", "Cidadão" com peso 5; "Educação" com peso 2 e "Desenvolver", "Cultura" e "Motivar" com peso 1. Assim, na visão dos docentes, a função social do IFES se relaciona fortemente com o mercado de trabalho, mas também, indica-se a função de fazer formação para cidadania e para o desenvolvimento dos alunos e do conhecimento.

Na pesquisa 02, diferente da pesquisa 01 , em que os docentes indicaram em sua maioria formar para o mercado de trabalho e a minoria indicou formar para a cidadania, sobre os objetivos da integração na educação profissional técnica de nível médio ao ensino médio, utilizaram com mais frequência as palavras "Trabalho", com peso 17 e "Mercado", com peso 13; "Educar" e "Formar", com peso 4; "Conhecimento" e "Cultura", com peso 3; "Técnicos" e "Social", com peso 2; e, "Produção" e "Universidade", com peso 1. Aqui, os docentes relacionam fortemente o mercado de trabalho com a oferta de cursos técnicos integrados ao ensino médio, mas também indicam outros objetivos, para além do emprego e do mercado de trabalho.

No entanto, na pesquisa 02, ficou claro que, pelos relatos orais no grupo focal, para os docentes, a principal função da instituição é formar para a cidadania. Mas entre formar uma ou outra direção, algumas dificuldades foram sinalizadas. Estas estão diretamente correlacionadas com os modos de conciliar formação de cidadãos com a formação técnica para inserção no mercado e no mundo do trabalho.

[...] a gente sabe teoricamente que é muito importante formar cidadão e eu acho que a gente até se esforça, mas acaba tendendo mais para o lado profissional. Pensa que se ele não tiver essa educação profissional muito sólida, ele não vai conseguir se inserir no mundo do trabalho [...]

Essa docente considera importante para o aluno a formação cidadã, no entanto, por trabalhar com um curso técnico, o educando acaba se formando para o lado mais técnico, não focando muito a formação cidadã. Tendo em vista que se trata de um curso integrado, tais objetivos não deveriam ser colocados em termos dicotômicos, mas como fins associados e constitutivos do projeto educativo do curso técnico integrado.

Não obstante essa contradição entre mercado e cidadania, na fala da professora, utiliza-se o termo "mundo do trabalho", e não "mercado", como na pesquisa 01, que tem um sentido muito mais amplo. Percebe-se que a docente proporciona ao aluno mais possibilidades do que apenas formar para o mercado. Ela ressalta que

[...] devido a essa preocupação (em formar um técnico), fica um pouco aquém a formação do cidadão, no meu ponto de vista, e ao passo que se a gente se preocupasse um pouco 
mais com a formação cidadã, que eu acho que é mais difícil adquirir, do que o conteúdo profissionalizante, o conteúdo profissionalizante eu penso que seria mais fácil para ele aprender do que atitudes de ser cidadão na verdade.
Segundo a profissional, a formação cidadã é mais difícil de ser adquirida do que a formação técnica proporcionada pelo curso. Alguns profissionais questionaram se é mesmo para ser cidadão que se forma o aluno do Ifes, destacam a capacitação técnica como um fator muito importante na hora de formar o aluno.

Uma das participantes elenca que é diferente a formação voltada para ser cidadão e para ser técnico. E com isso ela encerra a fala fazendo uma pergunta a seus colegas.

Ensinar a ser cidadão é diferente de ensinar a ser técnico. Já você ensinar a ser cidadão é mais complexo do que você ensinar uma pessoa a ser um técnico. E agora vou fazer uma pergunta: onde a gente aprende a ser cidadão? Será que é vindo para a escola?
Os conteúdos que compõem os cursos técnicos integrados têm a ver com essa dupla função, de formar para cidadania e para profissão. Mas para os docentes, existe uma prevalência entre formar o técnico e o cidadão. Essa dificuldade precisa ser melhor elucidada, do ponto de vista do plano de curso e nas concepções dos sujeitos no processo ensino-aprendizagem, para que os docentes do curso técnico venham a compreender a totalidade de sua função educativa prevista na própria Constituição, que afirma a finalidade da educação escolar no Brasil como "pleno desenvolvimento da pessoa, preparo para exercício da cidadania e qualificação para o Trabalho" (BRASIL, 1988, art. 205).

\subsection{Avaliação da integração}

Sobre a avaliação da integração no campus, a pesquisa 01 dá algumas indicações a partir de perguntas que tangenciam o modo como eles avaliam a integração das pessoas, das disciplinas e áreas, da sequência dos conteúdos, tendo em vista um diálogo em processo permanente com a gestão da integração.

Na pergunta "Que docentes de outras disciplinas você conhece?", obteve-se 6 em 31, ou seja, 19\% afirmam que conhecem totalmente os professores atuantes nas disciplinas da educação geral e do ensino técnico; 5 em 31, ou seja, 16\% afirmam que conhecem apenas alguns professores das disciplinas da educação geral; 4 em 11, 13\% afirmam que conhecem totalmente os professores das disciplinas do ensino técnico; 4 em 31, 13\% afirmam que

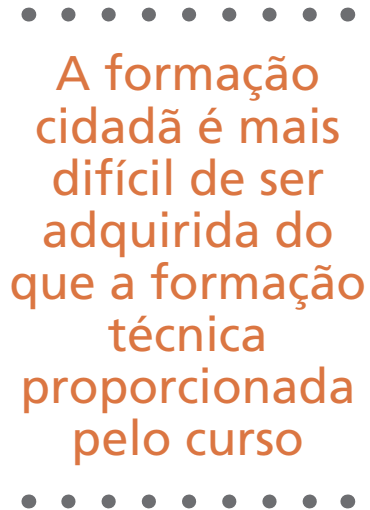

A formação cidadã é mais difícil de ser adquirida do que a formação técnica pelo curso 
conhecem todos os professores das disciplinas da educação geral e alguns professores do ensino técnico; 2 em 31, 6\% afirmam que conhecem todos os professores das disciplinas do ensino técnico e alguns professores da educação geral; 1 em 31, 3\% afirmam que conhecem totalmente os professores das disciplinas da educação geral; e 6 em 31, quer dizer, 19\% não responderam a questão. Nesse caso, pode-se observar que a integração das pessoas é condição básica para integração do currículo, mas não está garantida, pois nem todos se conhecem ou se encontram de modo a favorecer uma articulação interdisciplinar. Desse modo, pode-se supor que, mantendo-se este contexto, a tendência é que o conhecimento mútuo entre todos os docentes não esteja garantido.

Nessa mesma direção, a pesquisa 02 indica que o conhecimento recíproco dos profissionais da área técnica e propedêutica é frágil. Segundo os docentes, isso tem a ver um pouco com a rotatividade de professores do núcleo básico. Segundo os relatos, há professores atuando em vários lugares ao mesmo tempo e isso dificulta a participação deles, pois não possuem foco no curso em que atuam. Uma docente declara:

Em algumas disciplinas muda quatro vezes o professor de matemática durante o ano [...], é meio complicado a gente tentar fazer uma integração se as pessoas estão atuando em muitos locais. Então, eles nunca estão aqui para discutir, porque têm suas atribuições em outros locais.

Quando se troca muito de professores na área propedêutica ou se atua em vários cursos, a integração entre as pessoas fica prejudicada e o ensino integrado, fragilizado.

Será que todos os ingressantes na instituição querem atuar nos cursos integrados? Para tentar entender essa questão, na pesquisa 01, perguntou-se: "Quais cursos a instituição deveria priorizar?". Neste caso, entre 30 respondentes resultou que: 19 (2/3) sugerem o ensino integrado regular; 13 indicam a graduação; 11 (1/3), o Proeja técnico; 10 (1/3), os cursos técnicos nas formas concomitante e subsequente; 05, os cursos de pós-graduação e 2 apontam os cursos do tipo Proeja-FIC.

Interessante notar que a integração curricular mantém sua importância no contexto da instituição. Atribui-se a isso o fato de que, na visão dos docentes, os cursos técnicos integrados garantem alunos mais bem-selecionados, em razão do número maior de candidato por vaga, o que também ocorre nos cursos superiores. Talvez isso explique o pouco peso atribuído ao Proeja.

Na pesquisa 02, em reuniões, os docentes reiteram que a configuração híbrida do Ifes, onde profissionais atuam no ensino e na gestão de cursos muito diversos (da pós-graduação aos cursos FIC, passando pela gradua- 
ção e cursos técnicos, além da pesquisa e extensão), colabora-se com um possível movimento de descontinuidade na convivência entre eles. Além disso, esse processo confere pouca centralidade à atuação nos cursos técnicos integrados.

Na pesquisa 01, lançada a pergunta "Qual conhecimento possui sobre as outras disciplinas ministradas pelos outros decentes?", procurou-se entender sobre a integração dos conteúdos de ensino e das disciplinas. Sendo assim, as respostas indicaram que: 11 docentes em 31 (35\%) conhecem totalmente todas as disciplinas da educação geral e do ensino técnico; 5 em 31 (16\%) conhecem apenas algumas disciplinas da educação geral; 5 em 31 (16\%) afirmam ter conhecimento de todas as disciplinas do ensino técnico e algumas disciplinas da educação geral; 2 em 31 (6\%) declaram que conhecem apenas algumas disciplinas do ensino técnico; 1 em 31 (3\%) garante que conhece ou todas as disciplinas da educação geral e algumas do ensino técnico ou todas as disciplinas do ensino técnico e algumas disciplinas da educação geral. E 5 em 31 (16\%) não responderam essa questão.

Embora a matriz curricular seja parte integrante do plano de curso, o conjunto total de disciplinas e conteúdos dos cursos técnicos integrados e, apesar de ser um documento acessível, nem todos sabem que conteúdos os alunos estão aprendendo em uma determinada turma/curso/ano/série.

Ainda na pesquisa 01, para saber sobre a integração dos tempos, questionou-se: "Qual conhecimento possui sobre o andamento dos conteúdos ministrados pelos outros docentes?". Obteve-se, então: 9 em 31 (29\%) afirmam que acompanham apenas sua própria sequencia didática; 7 em 31 (22,6\%), algumas disciplinas do ensino técnico; 5 em 31 (16,1\%), algumas disciplinas da educação geral; 4 em 31 (12,9\%) afirmam que acompanham totalmente as disciplinas da educação geral e do ensino técnico; 3 em 31 $(9,7 \%)$, totalmente as demais disciplinas do ensino técnico; 2 em 31 (6,5\%) não responderam essa questão; 1 em 31 (3,2\%) afirma que acompanha totalmente as demais disciplinas da educação geral. Assim, infere-se que há uma tendência de o professor se preocupar com seu fazer individual e compartilhar pouco de suas sequências didáticas, eximindo-se da colaboração entre os demais professores.

A escolha pela oferta dos cursos integrados demanda uma postura diferenciada da organização institucional de ensino, que precisa se indagar permanentemente sobre como os docentes avaliam a integração curricular.

\subsection{A gestão da integração}

Um aspecto que ganhou relevância na pesquisa 02 tem a ver com a gestão da integração. Para os sujeitos da pesquisa, esse aspecto pode interferir 
no processo de integração curricular, favorecendo ou não a integração das pessoas, dos tempos, dos espaços e dos conteúdos de ensino na instituição.

Como se sabe, a oferta de cursos técnicos integrados está amparada tanto na Constituição federal, nas Leis de Diretrizes e Bases e nas Diretrizes Curriculares Nacionais quanto na lei de criação dos Institutos Federais. Esta, mais especificamente, preconiza uma quantidade mínima de matrículas para esse tipo de curso. De modo mais particular, do ponto de vista local, ao nível do Instituto Federal e de seus campi, esse tipo de curso também encontra uma série de prescrições apresentadas em plano de ensino, regimento e estatuto da instituição, que preveem a organização do currículo e as formas de acesso. Mas em nenhum lugar há orientações mais claras de como deve ser feita a integração e como ela deve ser gerida, incentivada ou quais os procedimentos que a gestão deve adotar ou cobrar dos docentes para que ela seja fortalecida.

A tendência natural que se percebe nos relatos é a de que a lógica da implementação e operacionalização da matriz curricular combina dois processos de fragmentação e de justaposição. A fragmentação tem a ver com os tempos, os conteúdos, as pessoas e os espaços. Isso ocorre quando cada docente, por sua formação e por sua rotina de trabalho, cuida do que ensina a partir de uma sequência didática que se enquadra nos limites dos tempos e dos espaços a eles disponibilizados no plano de ensino e na infraestrutura do campus. A justaposição tem mais a ver com os conteúdos e avaliações que se juntam na cabeça dos alunos, mas não se articulam, senão pelo esforço dos discentes em fazer as relações entre os diversos saberes que compõem a totalidade da realidade e de sua formação.

Os relatos dão a ver várias situações que impedem a ocorrência de integração entre pessoas, tempos, espaços e conteúdos. O primeiro obstáculo diz respeito ao fato de não saberem integrar os conteúdos de diferentes campos do saber. Segundo uma docente do curso de Edificações: "a gente tem que aprender a integrar e eu não sei integrar com a educação física, por exemplo. Isso pode acontecer com outras disciplinas também".

Paralelamente, outro docente, mais antigo da instituição, afirma que

na época da escola técnica, só havia oferta de cursos técnicos e todos os professores e alunos estavam envolvidos como docentes e/ou discentes de curso técnico-profissionalizante de 2 o grau. Hoje em dia, trabalhamos com vários tipos de cursos diferentes.

Uma reclamação constante dos professores é a falta de oportunidade para que se encontrem. Segundo um dos docentes participante do grupo focal, “a gente só tem esses encontros no conselho de classe, que é só nota e falta, 
nota e falta, a parte do conteúdo a instituição não propicia nesses momentos de encontro".

Uma professora propõe que seja institucional a convocação dos professores, para que eles possam participar dos eventos de integração (como as reuniões de pesquisa), dentro da própria instituição. Com isso, para ela, a participação dos profissionais em reuniões que promovem a integração seria mais significativa. Os diversos compromissos que os docentes têm dentro da instituição acabam não proporcionando momentos de encontro entre eles, gerando desencontro frequente entre os profissionais do núcleo técnico e do núcleo básico.

Há uma reclamação dos professores em relação a uma resolução dentro da instituição que "obriga" o profissional a um número fixo de horas em aulas durante a semana. "A gente tem uma resolução de carga horária, que exige ter 18, sei lá quantas horas de aula para atender [...]". E segundo eles, isso não favorece para que o curso seja integrado. "Essa resolução não promove integração, ela quer colocar o professor direto na sala de aula e não o coloca dentro de uma coordenadoria integrada com os demais professores [...]". Assim, o profissional não pode estar em interação com outros em tempos e espaços de outras áreas.

Percebem-se muitos impasses em relação à integração dentro do Curso Técnico em Edificações integrado ao Ensino Médio, no entanto, observa-se que os próprios profissionais atuantes no curso pensaram possíveis ações para que a integração possa de fato acontecer.

Algumas falas de coordenadores de cursos revelam "a dificuldade em lidar com esta variedade de cursos. Fica difícil até reunir as pessoas que estão demandadas por outros tipos cursos, como pós-graduação, FIC etc.".

Para os sujeitos da pesquisa, a escassez de encontros impede maior integração, e desse modo fica difícil fazer confluir os tempos, os espaços e os conteúdos de ensino, no sentido da construção coletiva de iniciativas que levam à interdisciplinaridade e à integração educacional. Por outro lado, a gestão não tem mobilizado de maneira eficaz os docentes nesse sentido, de modo que cada um vai desenvolvendo o seu conteúdo sem necessariamente relacionar-se com os colegas. Faz-se sobreposição de conteúdos e as avaliações demandam cada vez mais dos alunos, que precisam saber administrar 14 disciplinas por ano/série, com provas e atividades desconectadas entre si.

A própria gestão do campus também está multifocada, por ter que administrar grande número de alunos e diversos tipos de curso. Os gestores e docentes se perguntam o que fazer para criar uma estratégia de trabalho de gestão que fortaleça, em longo prazo, os cursos técnicos integrados. Se 
a instituição se tornou uma entidade pública híbrida, com atribuições em todos os níveis e que atende a muitas demandas diferenciadas, os cursos técnicos, com esforço da coordenação, do corpo pedagógico e em conjunto com os docentes, têm que dar conta desse processo. Entretanto, é notável a necessidade de valorização das práticas integradoras mobilizadas por alguns docentes, reconhecendo a importância de suas iniciativas particulares, na tentativa de romper com o isolamento disciplinar.

\subsection{Práticas de integração}

Apesar dos problemas listados, os sujeitos da pesquisa relatam muitas iniciativas integradoras. Alguns profissionais já têm certa familiaridade com as práticas de integração e muitos deles citaram exemplos de como fazem para aplicá-las em suas aulas. Entre as formas de integração possíveis, destaca-se um processo, mais detidamente, em relação aos conteúdos obrigatórios da instituição.

Na pesquisa 02, uma professora afirma que procurou integrar conteúdos de diferentes disciplinas em sua aula. Relata: "eu trabalhei nesse bimestre a integração das etapas do projeto arquitetônico inseridas na química, na física, na matemática, no português".

Para os docentes, a conexão entre os assuntos disciplinares aumenta o interesse dos alunos. Um docente afirma: "nossa, mas que legal, vocês conseguiram visualizar bastante". E "ainda começaram a se aprofundar mais do que no projeto arquitetônico, colocando em prática a construção civil [...]". Nessa prática a professora conseguiu levar em conta aspectos da construção civil com outras matérias do curso de Edificações do núcleo básico do curso. Evidencia-se, assim, que se pode realizar a integração de uma forma bem simples e com muito significado para os alunos.

Outro exemplo foi relatado pelo coordenador de Edificações, sobre o trabalho de docente da disciplina de Língua Portuguesa, segundo ele: “a partir de uma disciplina da área técnica, que obtinha um perfil de redação de relatórios, nós percebemos a dificuldade dos alunos com a parte da redação e convidamos à colaboração a professora de português".

Outra docente dispõe do seu interesse e de sua iniciativa em integrar, considerando a integração "uma experiência muito benéfica e a maneira como a gente vai buscar na física, na matemática, e na química alguns conceitos para explicar a parte técnica".

Outra ação integradora em visibilidade é realizada por meio de palestras com conteúdos que os alunos ainda vão estudar. 
Por exemplo, o coordenador do curso vai até a sala de aula no início do ano e faz uma palestra sobre a área técnica, pois como podemos observar na matriz curricular do plano de curso de Edificações, no primeiro ano/série do curso, os alunos têm pouco contato com as matérias técnicas, com essa palestra os alunos produzem um relatório e conseguem se inteirar do conteúdo a ser estudado e que é avaliado pela professora de Português.

Outra proposta em destaque apresentada por um professor da área técnica é a de relacionar a matéria que ele leciona com outras disciplinas do núcleo básico: "seria interessante que tivesse uma reunião, por exemplo, com geografia, dando ideias de como eles podem usar essa matéria para a nossa realidade. Porque eles não são obrigados também a conhecerem a nossa realidade $[\ldots]^{\prime \prime}$.

Ao propor aos professores da área técnica que se reúnam com os profissionais do ensino médio, um professor procura estreitar os laços entre as coordenadorias. Menciona que para o professor de geografia integrar sua disciplina a outra de caráter técnico, precisa conhecer o planejamento da aula. Desse modo, há necessidade de um encontro para se falar sobre uma outra matéria, tendo em vista a não obrigatoriedade de conhecimento das especificidades de todas as disciplinas. Ainda mais levando em consideração o fato de que não leciona somente em um curso.

Exemplos que unificam a parte de gestão da instituição também fizeram parte das possibilidades de integração propostas pelos professores. Uma das possibilidades no âmbito da gestão seria institucionalizar palestras apresentadas pelos professores.

Eu sou professor e já receberia, no início do ano, uma programação dizendo em que determinada data eu teria que ir fazer uma palestra sobre determinado assunto para determinada turma. Isso já viria institucionalizado.

Um ponto interessante que os professores abordaram, ainda no aspecto de realizar a integração por meio de palestras, é que eles pensaram em procurar um tema que se relacionasse com as duas matérias, uma técnica e uma propedêutica, para que a palestra pudesse fazer mais sentido ao aprendizado do aluno e que também contribuísse com a disciplina e a avaliação do professor do propedêutico.

Nessa integração que você está falando é interessante a utilização de momentos de a área técnica se inserir no conteúdo da área propedêutica. Na aula de história, vou tentar buscar lá também a história do surgimento do material concreto, falando das instalações hidrossanitárias, mostrar como é o desenvolvimento da capitação de água ao longo da história, como e quais são as primeiras evidências de que 
o ser humano chegou e encontrou um fonte de água potável e conduziu para outro lugar e dali foi se desenvolvendo o que na Roma Antiga, por exemplo, os aquedutos eram feitos de tubos de chumbo que conduziam pra aquele povo todo, que tinha toda uma ligação com chumbo que era um metal pesado [...].

Quando se integra uma matéria com a outra, pode-se fazer uma avaliação conjunta daquele conteúdo que foi estudado. Assim, o aluno consegue ter melhor aproveitamento do assunto, além de menores quantidades de avaliações durante o período: "[...] um trabalho vale para as duas disciplinas, então o aluno em vez de fazer duas avaliações ele faz uma".

Uma observação interessante de uma professora da área técnica é a de que em todas as reuniões os docentes do ensino técnico sempre esperavam que os professores do núcleo básico integrassem as matérias tecnológicas. Ela então propõe o inverso, que os profissionais do núcleo técnico procurem os professores do núcleo básico para de alguma forma potencializar a integração, deixando uma reflexão aos colegas:

Um ponto que a gente falou bastante é o professor de química e física saber do nosso futuro. E quantas vezes eu na minha matéria lá, Instalações Elétricas Básicas, Fios e Eletricidade, quantas vezes eu tive a atitude de ir lá na coordenação de física, bater na porta e perguntar 'quem é o professor de física aqui'? É mais confortável para mim do que para ele.

Pode-se perceber a importância de práticas mobilizadoras em direção aos colegas de outras disciplinas para que a integração ocorra. Pressupõe-se que a receptividade do colega a partir desse movimento pode consolidar ou inviabilizar esse processo.

Apesar das iniciativas dos docentes, muitos têm uma posição pessimista em relação à qualidade da integração. Nas pesquisa 01, foi indagado: "Qual a qualidade da integração curricular?". Nesse caso, os docentes classificam a oferta de cursos técnicos integrados como uma política: a) viável, para $42 \%$ (14 em 33); b) problemática, para 27\% (09 em 33); c) não responderam, 12\% (04 em 33); d) avançada, para 9\% (3 em 33); e) inviável, mas necessária para 3\% (01 em 33) e f) dispensável e desnecessária, para 3\% (01 em 33). Ou seja, agrupados os respondentes em dois grupos que apoiam ou não essa oferta, apresentaram-se opiniões favoráveis, 51\% (17 em 33); e desfavoráveis, 48\% (16 em 33). Esse panorama dá a ver uma adesão problemática à integração, além disso, a avaliação dos docentes sobre esta oferta escolar precisa avançar muito para que sua implementação não dependa apenas de suas iniciativas, mas que seja assumida como ação institucional. 


\section{Considerações finais}

Existem enormes desafios para a realização da integração, que vão desde a dificuldade de universalização dos cursos técnicos integrados em razão de seu alto custo e de sua complexidade tecnológica à implementação da integração do ensino médio. A educação profissional técnica de nível médio exige uma organização curricular que distribua, mas também faça convergir as pessoas, os espaços, os tempos e os conteúdos no processo de implementação curricular.

A partir das análises desenvolvidas durante esse estudo, observaram-se obstáculos e também inúmeras possibilidades/viabilidades à prática da integração dentro do curso. Vislumbra-se, assim, um possível caminho para que a integração de pessoas, espaços, tempos e conteúdos seja, de fato, concretizada dentro do curso técnico integrado em Edificações (Ifes - Campus Vitória).

Considera-se que, para vencer as dificuldades que fazem dos cursos técnicos integrados uma política contra-hegemônica, tanto no nível local como no nível nacional, é necessário criar condições aos alunos, para que consigam se organizar e dar conta do número elevado de avaliações e disciplinas, muitas vezes, totalmente desconhecidas para os egressos do ensino fundamental.

A instituição de ensino também deve investir em formação pedagógica, de modo a modificar o comportamento e as concepções dos docentes bacharéis e licenciados. É necessário superar a fragmentação intrínseca que existe na formação inicial dos docentes, cujo foco dialoga mais com sua formação específica e menos com a interdisciplinaridade e a integração curricular.

É necessário promover engajamento dos docentes, no sentido de fazê-los querer sair de suas zonas de conforto e de suas "caixinhas de saberes", que Ihes conferem um pseudopoder na estrutura dos cursos em que atuam.

O enfrentamento desses desafios tem demanda em um conjunto de estratégias de gestão e de soluções pedagógicas que possam ir além da vontade dispersa e espontânea de alguns docentes que, no seu cotidiano, tentam juntar esforços para superar os processos de fragmentação pedagógica e setorização profissional, típicas da divisão do trabalho na sociedade capitalista, que tende a separar, escalonar, sequenciar e hierarquizar o conhecimento e as pessoas envolvidas no ensino.

Para integrar e não justapor ou fragmentar as pessoas, os tempos, os conteúdos e os espaços, é fundamental ter e difundir uma perspectiva de formação humana integral, que se baseie nos princípios da educação tecnológica, da politecnia e da formação omnilateral, tendo como base eixos orientadores

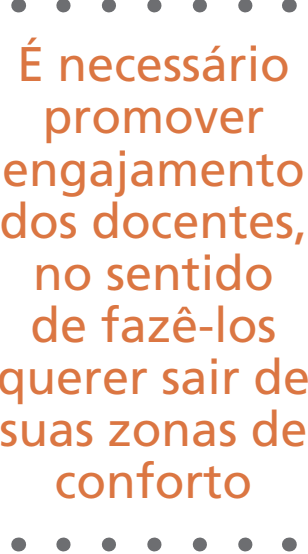


fundamentais: a) o reconhecimento dos saberes dos sujeitos do processo ensino-aprendizagem; b) o trabalho como princípio educativo; c) a pesquisa como princípio pedagógico e d) superação das hierarquias e das sequências dos processos de ensino.

Ficou evidenciado que a oferta de cursos técnicos integrados, apesar de sua consistência pedagógica e amplitude formativa preconizada, não é uma política que conta com a unanimidade dos envolvidos na Rede Federal. A sua implementação revela que, do ponto de vista dos docentes, inúmeros são os obstáculos à integração das pessoas, dos tempos, dos espaços e dos conteúdos, o que se relaciona com questões mais amplas, de ordem epistemológica, pedagógica e política, de imprescindível superação na gestão e no ensino dos cursos técnicos integrados. Também se conclui que esse tipo de curso se constitui em uma proposta contra-hegemônica tanto no nível macro (políticas nacionais de EPT) como no nível micro (no Ifes e nos campi), cujos embates precisam ser enfrentados no dia a dia da Rede Federal de cada campi.

Baseados em uma perspectiva marxiana, que se ancora nos fundamentos de um formação humana integrada, integradora e omnilateral, percebe-se que o ensino médio integrado realizado na Rede Federal, embora enseje a superação do dualismo, da alienação e da reprodução da força de trabalho, precisa modificar sua lógica interna à sua implementação. Ficou evidenciado que a oferta de cursos técnicos integrados, apesar de sua consistência pedagógica e amplitude formativa preconizada, não é uma política que conta com a unanimidade dos envolvidos dentro da Rede Federal. Por outro lado, observa-se que, deixada à sua própria sorte, o currículo mais fragmenta e se justapõe do que se integra.

Entretanto, a escola pública unitária e de qualidade tem na Rede Federal condições objetivas favoráveis para uma formação adequada, mas a cultura escolar e os interesses em jogo na instituição fazem esvaziar as dimensões quantitativas da oferta dessa modalidade de ensino e comprometem a viabilidade pedagógica e a força política daquilo que se denomina a proposta mais avançada em termos da oferta de educação básica e profissional no Brasil.

Como afirmam Moura, Lima Filho e Silva (2015), a existência da oferta do ensino médio integrado à educação profissional de nível médio, modelo que aponta para uma formação ominilateral, ao mesmo tempo em que se constitui meio de transformação da sociedade também é produto dessa transformação, logo, não basta mudar a educação, é necessário mudar a sociedade.

Atualmente, a sociedade brasileira vive não apenas a reiteração dos obstáculos à integração curricular, mas também a possibilidade de retrocesso em relação ao ensino médio integrado à educação profissional técnica de nível 
médio. As novas políticas que emergem do governo pós-Dilma ensejam esvaziar o currículo do pós-ensino fundamental, colocando a educação técnica como elemento ainda mais desconectado da formação propedêutica. Tal situação reforça ainda mais as preocupações trazidas por este artigo e reitera a necessidade de maior aprofundamento das pesquisas sobre este tema.

\section{Notas}

${ }^{1}$ Na pesquisa 01, foi aplicado um formulário a 39 docentes do Ifes. Foi utilizada ferramenta do Excel para contar as palavras mais repetidas e realizada análise qualitativa das perguntas abertas.

${ }^{2}$ Na pesquisa 02, nos anos de 2013 e 2014, foi realizada uma série de reuniões com grupos focais de professores que atuam nos cursos técnicos integrados em dois campi de uma unidade do Ifes.

\section{Referências}

BIANCHO FILHO, A.; SILVEIRA, G. A.; OLIVEIRA, N. C. Caminhos para a construção de uma política de integração curricular da educação profissional com a EJA: a experiência do Centro Educacional Irmã Maria Regina Velanes Regis no âmbito da SEEDF. Revista Com Censo, Brasília, DF, n. 5, p. 79-85, maio 2016. Edição Especial, n. 2.

BRASIL. Decreto n. 2.208, de 17 de abril de 1997. Regulamenta o $\S 2^{\circ}$ do art. 36 e os arts. 39 a 42 da Lei Federal n. 9.394/96, que estabelece as diretrizes e bases da educação nacional. Diário Oficial da União, Brasília, DF, 18 abr. 1997. Revogado pelo decreto n. 5.154, de 2004.

BRASIL. Constituição (1988). Constituição da República Federativa do Brasil. Brasília, DF: Senado, 1988. cap. 3: Da educação, da cultura e do desporto, Seção 1: da educação.

BRASIL. Ministério da Educação. Secretaria de Educação Profissional e Tecnológica. PROEJA: Programa Nacional de Integração da Educação Básica na Modalidade de Jovens e Adultos: documento base. Brasília, DF, 2006.

BREMER, M. A. S.; KUENZER, A. Z. Ensino médio integrado: uma história de contradições. Trabalho apresentado no Anped Sul: Seminário de Pesquisa em Educação da Região Sul, 9., 2012. Disponível em: <http://www.ucs.br/etc/conferencias/index. php/anpedsul/9anpedsul/paper/viewFile/2217/208>. Acesso em: set. 2013.

CIAVATTA, M.; RAMOS, M. N. Ensino médio e educação profissional no Brasil: dualidade e fragmentação. Revista Retratos da Escola, Brasília, DF, v. 5, n. 8, p. 27-41, jan./jun. 2011. 
FRIGOTTO, G.; CIAVATTA, M.; RAMOS, M. (Org.). Ensino médio integrado: concepção e contradições. São Paulo: Cortez, 2005.

INSTITUTO FEDERAL DO ESPÍRITO SANTO. Resolução n. 62, de 10 de novembro de 2010. Aprova alteração do Estatuto do Instituto Federal de Educação, Ciência e Tecnologia do Espírito Santo. Diário Oficial da União, Brasília, DF, 11 nov. 2010. Seção 1, p. 10-12.

MENEZES, R. C. D. A adoção do currículo do ensino médio integrado e os desafios da prática pedagógica nessa perspectiva curricular: um estudo avaliativo. Trabalho apresentado no ENDIPE: Encontro Nacional de Didática e Práticas de Ensino, 16, Campinas, 2012.

MORAES, C. S. V.; ALAVARSE, O. M. Ensino médio: possibilidades de avaliação. Educação \& Sociedade, Campinas, v. 32, n. 116, p. 807-838, jul./set. 2011.

MOURA, D. H. A integração curricular da educação básica na modalidade de jovens e adultos (Proeja). Cadernos de Pesquisa em Educação, Vitória, v. 19, n. 39, p. 30 49, jan./jun. 2014.

MOURA, D. H.; LIMA FILHO, D. L.; SILVA, M. R. Politecnia e formação integrada: confrontos conceituais, projetos políticos e contradições históricas da educação brasileira. Revista Brasileira de Educação, v. 20, n. 63, p. 1057-1080, 2015.

RAMOS, M. N. Concepção do ensino médio integrado. [S.I.: S.n., 2007]. Disponível em: <http://www.iiep.org.br/curriculo_integrado.pdf>. Acesso em: set. 2010.

RAMOS, M. N. Ensino médio integrado: da conceituação à operacionalização Cadernos de Pesquisa em Educação, Vitória, v. 19, n. 39, p. 15-29, jan./jun. 2014.

SILVA, M. R. A política de integração curricular no âmbito do Proeja: entre discursos, sujeitos e práticas. Ensaio: avaliação e políticas públicas em educação, Rio de Janeiro, v. 19, n. 71, p. 307-326, abr./jun. 2011.

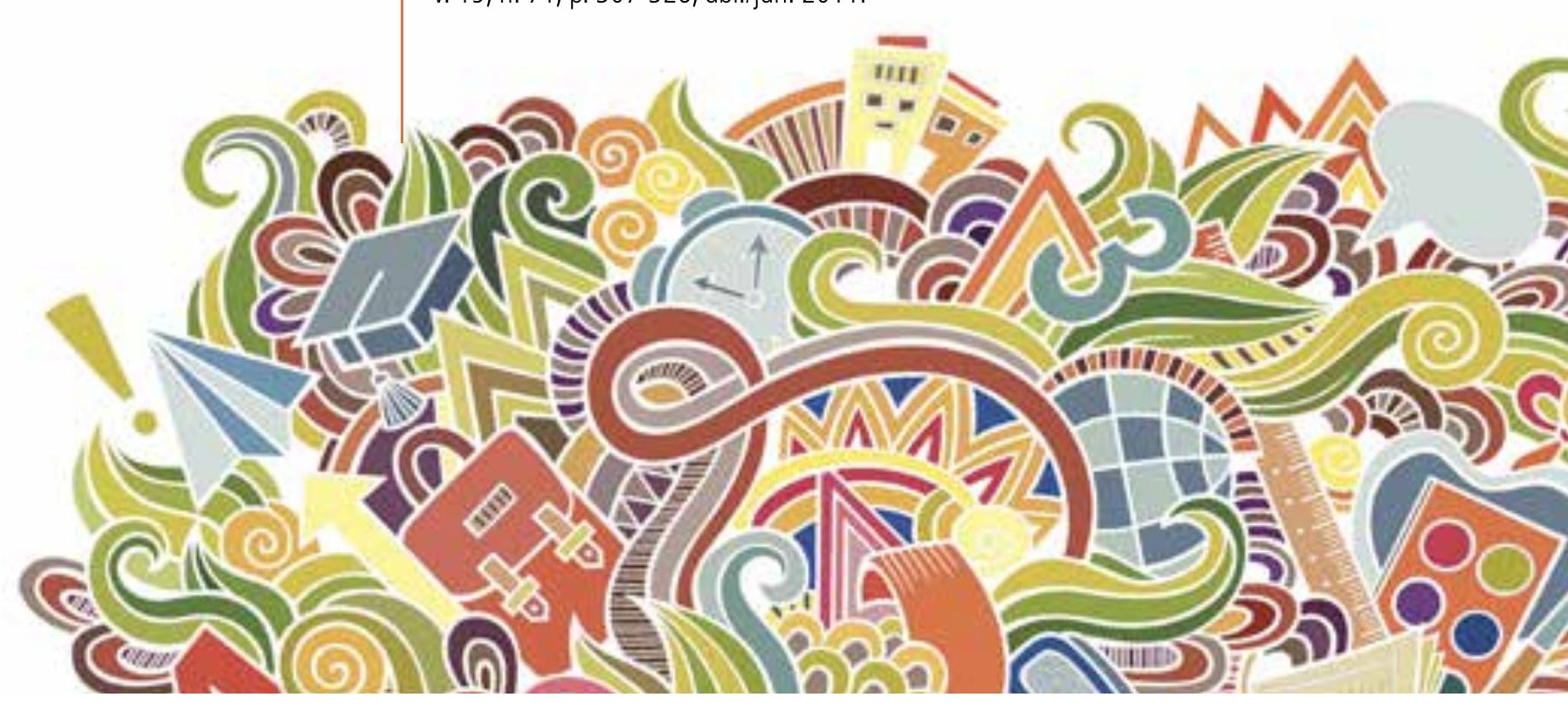

B. Téc. Senac, Rio de Janeiro, v. 43, n. 1, p. 140-159, jan./abr. 2017. 